\title{
An updated meta-analysis of 23 case-control studies on the association between miR-34b/c polymorphism and cancer risk
}

\author{
Hua Li ${ }^{1, *}$, Shuling Diao ${ }^{2, *}$, Jingsen $\mathrm{Li}^{2}$, Baoxin Ma², Shuanghu Yuan ${ }^{3}$ \\ ${ }^{1}$ Department of Oncology, The Affiliated Hospital of Binzhou Medical University, Binzhou, Shandong 256603, China \\ ${ }^{2}$ Department of Cardiology, The Affiliated Hospital of Binzhou Medical University, Binzhou, Shandong 256603, China \\ ${ }^{3}$ Department of Radiotherapy, Shandong Cancer Hospital and Institute, Jinan, Shandong 250117, China \\ *These authors have contributed equally to this work
}

Correspondence to: Baoxin Ma, email: sfdbh2006@sohu.com

Keywords: rs4938723, polymorphism, cancer risk, systematic review, meta-analysis

Received: October 15, $2016 \quad$ Accepted: February 27, 2017 Published: March 17, 2017

Copyright: Li et al. This is an open-access article distributed under the terms of the Creative Commons Attribution License (CC-BY), which permits unrestricted use, distribution, and reproduction in any medium, provided the original author and source are credited.

\section{ABSTRACT}

The association between in microRNA-34b/c gene rs4938723 polymorphisms and cancer risk remains inconclusive. This meta-analysis was performed to analyze the association between microRNA-34b/c rs4938723 polymorphism and risk for cancer development. In total, 304 studies from PubMed, Embase, Web of Science, Wanfang, and Chinese National Knowledge Infrastructure databases were examined, and 23 studies were included in this meta-analysis. The 23 selected studies involved 10,812 cancer cases and 11,719 controls. Odds ratios (ORs) and $\mathbf{9 5 \%}$ confidence intervals (CIs) were calculated to measure the strength of the association. Our results indicate a significant association between the rs4938723 polymorphism and cancer risk in the overdominant model ( $P$ heterogeneity $=0.018, O R=1.093$, and $95 \% \mathrm{CI}=1.015-1.177$ for CT vs. CC/TT). Using a stratified subgroup analysis, rs4938723 polymorphisms were associated with an increased risk for hepatocellular carcinoma, but decreased risk for colorectal, gastric, and esophageal squamous cell cancer. These findings indicate that the rs4938723 gene is a susceptible locus for cancer.

\section{INTRODUCTION}

Cancer is one of the most serious public health problems worldwide [1]. Intensive efforts have been undertaken to improve the efficacy of cancer diagnosis and therapy; however, the overall survival time of cancer patients is still short $[2,3]$. Further studies on the risk factors, biomarkers, and therapeutic targets for cancer should reduce the cancer burden. Emerging evidence has revealed that genetic factors, such as single nucleotide polymorphisms (SNPs), influence cancer development, treatment efficacy, and survival time of cancer patients [2].

Mature microRNAs (miRNAs) are a class of endogenous, single-stranded, and non-protein-coding small RNAs, which play an important role in tumorigenesis and cancer progression [4-6]. The SNPs in the genomic miRNA sequences influence miRNA-dependent regulation and alter tumor susceptibility $[7,8]$.

The microRNA-34 (miR-34) family comprises three miRNAs, namely, miR-34a, miR-34b, and miR-34c [9]. The miR-34b/c gene rs4938723 has been associated with hepatocellular and colorectal cancer [10-12]. However, updated, recent meta-analyses of the rs4938723 association with cancer risk have been limited. In this study, we have systematically reviewed the published data, and integrated all published studies to evaluate the association between rs4938723 polymorphism and cancer risk.

\section{RESULTS}

\section{Study characteristics}

Relevant studies from the PubMed, Embase, Web of Science, Wanfang, and Chinese National Knowledge Infrastructure databases were examined. A flowchart of the selected studies is presented in Figure 1. In total, 304 studies were searched (288 from the databases and 16 using a manual search). 108 duplicated retrieval articles were excluded from this study. In addition, 158 records were excluded because of improper titles and/or abstracts. 38 eligible studies were selected for a detailed evaluation. From these, 16 articles were excluded from this study 
according to the inclusion and exclusion criteria. Finally, 22 original articles containing 23 studies were included in the meta-analysis [7, 13-33]. The characteristics of the studies included are listed in Table 1. From the 23 studies, 20 were on patients of Asian descent, two were on patients of Caucasian descent, and one was on patients of African descent.

The 23 selected studies involved 10,812 cases and 11,719 controls. Among these studies, four studies were related to esophageal squamous cell cancer, three to hepatocellular cancer, three to breast cancer, three to lymphocytic leukemia, two to colorectal cancer, and two studies were related to gastric cancer. Only one study each was related to cervical cancer, papillary thyroid carcinoma, renal cell cancer, nasopharyngeal carcinoma, prostate cancer, and osteosarcoma. The genotype distribution in the controls was compatible with the Hardy-Weinberg equilibrium (HWE) in all 23 studies. The quality scores for the individual studies ranged from 4 to 10 , and the median score was 8.0.

\section{Main analysis results}

In the meta-analysis of the 23 eligible studies, genotype CT was significantly associated with cancer susceptibility in the overall population (overdominant model CT versus CC/TT: $\mathrm{P}_{\mathrm{H}}=0.018, \mathrm{OR}=1.093$, and $95 \%$ $\mathrm{CI}=1.015-1.177$ ), as shown in Table 2 and Figure 2. No association between rs4938723 polymorphism and cancer risk was observed in the allele, genotype, dominant, and recessive models.

\section{Subgroup analysis results}

In Asian and Caucasian populations, no significant association was observed in any genetic models. For hepatocellular carcinoma, the rs4938723 polymorphism was associated with an increased cancer risk in the comparison model (allele $\mathrm{C}$ versus $\mathrm{T}$ : $\mathrm{P}_{\mathrm{H}}=0.113$, OR $=1.114$, and $95 \% \mathrm{CI}=1.007-1.233)$, genotype model (CT versus TT: $\mathrm{P}_{\mathrm{H}}=0.121, \mathrm{OR}=1.191$, and $95 \% \mathrm{CI}=$ 1.033-1.373), and overdominant model (CT vs. CC/TT: $\mathrm{P}_{\mathrm{H}}=0.195, \mathrm{OR}=1.157$, and $\left.95 \% \mathrm{CI}=1.010-1.324\right)$. For lymphocytic leukemia, no association was observed in any genetic models. The rs4938723 polymorphism decreased the risk for colorectal cancer in the genotype (CC vs. TT: $\mathrm{P}_{\mathrm{H}}=0.342, \mathrm{OR}=0.658$, and 95\% CI $\left.=0.470-0.923\right)$ and recessive models (CC vs. CT/TT: $\mathrm{P}_{\mathrm{H}}=0.519$, OR $=0.672$, and $95 \% \mathrm{CI}=0.485-0.930$ ). In addition, the rs4938723 polymorphism was negatively associated with

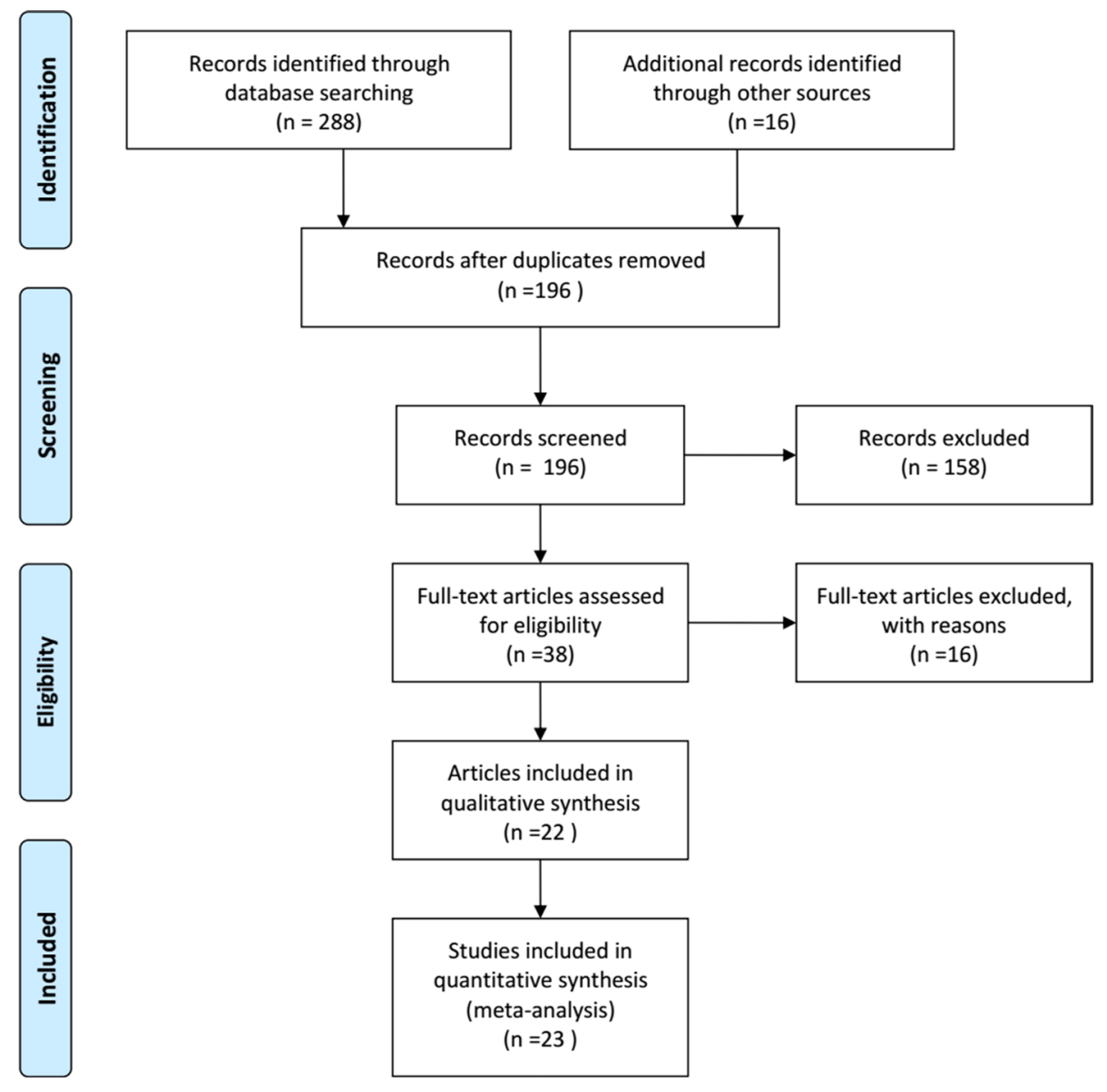

Figure 1: Flow chart of studies selection in this meta-analysis. 


\section{Table 1: Main characteristics of studies included in the meta-analysis}

\begin{tabular}{|c|c|c|c|c|c|c|c|c|c|c|c|c|c|c|c|c|c|c|c|}
\hline \multirow[b]{2}{*}{ Author } & \multirow[b]{2}{*}{ Year } & \multirow[b]{2}{*}{ Country } & \multirow[b]{2}{*}{ Ethnicity } & \multirow[b]{2}{*}{ Cancer type } & \multirow[b]{2}{*}{$\begin{array}{l}\text { Genotyping } \\
\text { methods }\end{array}$} & \multirow[b]{2}{*}{ Cases } & \multirow[b]{2}{*}{ Controls } & \multicolumn{5}{|c|}{ Case } & \multicolumn{5}{|c|}{ Control } & \multirow{2}{*}{$\begin{array}{l}\text { Pvalue } \\
\text { for HWE } \\
\text { test in our } \\
\text { controls } \\
\end{array}$} & \multirow[b]{2}{*}{ Quality } \\
\hline & & & & & & & & TT & CT & $\mathrm{CC}$ & $\mathrm{T}$ & C & TT & CT & $\mathrm{CC}$ & $\mathrm{T}$ & C & & \\
\hline Hashemi-1 & 2016 & Iran & Asian & $\mathrm{PC}$ & PCR-RFLP & 151 & 152 & 85 & 56 & 10 & 226 & 76 & 109 & 38 & 5 & 256 & 48 & 0.46 & 8 \\
\hline Hashemi-2 & 2016 & Iran & Asian & LL & PCR-RFLP & 110 & 120 & 77 & 31 & 2 & 185 & 35 & 62 & 52 & 6 & 176 & 64 & 0.24 & 5 \\
\hline Sanaei & 2016 & Iran & Asian & $\mathrm{BC}$ & PCR-RFLP & 263 & 221 & 125 & 115 & 23 & 365 & 161 & 100 & 106 & 15 & 306 & 136 & 0.06 & 4 \\
\hline Yuan & 2016 & China & Asian & $\mathrm{CC}$ & PCR-RFLP & 328 & 568 & 117 & 175 & 36 & 409 & 247 & 242 & 258 & 68 & 742 & 394 & 0.95 & 7.5 \\
\hline Chen & 2015 & China & Asian & PTC & PCR-RFLP & 784 & 1006 & 271 & 402 & 111 & 944 & 624 & 456 & 451 & 99 & 1363 & 649 & 0.41 & 8 \\
\hline Pan & 2015 & China & Asian & $\mathrm{GC}$ & PCR-RFLP & 197 & 289 & 102 & 76 & 19 & 280 & 114 & 121 & 137 & 31 & 379 & 199 & 0.4 & 7.5 \\
\hline Tong & 2015 & China & Asian & LL & Taqman assay & 570 & 673 & 254 & 281 & 35 & 789 & 351 & 301 & 296 & 76 & 898 & 448 & 0.8 & 10 \\
\hline Yang & 2014 & China & Asian & $\mathrm{GC}$ & PCR-RFLP & 419 & 402 & 193 & 186 & 40 & 572 & 266 & 156 & 184 & 62 & 496 & 308 & 0.53 & 7.5 \\
\hline Zhang-1 & 2014 & China & Asian & $\mathrm{RCC}$ & Taqman assay & 710 & 760 & 302 & 324 & 84 & 928 & 492 & 352 & 344 & 64 & 1048 & 472 & 0.12 & 8.5 \\
\hline Zhang-2 & 2014 & China & Asian & ESCC & Taqman assay & 1109 & 1275 & 489 & 536 & 84 & 1514 & 704 & 569 & 573 & 133 & 1711 & 839 & 0.52 & 10 \\
\hline $\mathrm{OH}$ & 2014 & Korea & Asian & $\mathrm{CRC}$ & PCR-RFLP & 545 & 428 & 272 & 233 & 40 & 777 & 313 & 216 & 171 & 41 & 603 & 253 & 0.4 & 7 \\
\hline $\mathrm{Li}$ & 2013 & China & Asian & NPC & PCR-RFLP & 217 & 360 & 82 & 104 & 31 & 268 & 166 & 168 & 155 & 37 & 491 & 229 & 0.89 & 9 \\
\hline Han & 2013 & China & Asian & $\mathrm{HCC}$ & $\begin{array}{l}\text { Fluorescent- } \\
\text { probe qRT-PCR }\end{array}$ & 1013 & 999 & 451 & 444 & 118 & 1346 & 680 & 456 & 424 & 119 & 1336 & 662 & 0.18 & 10 \\
\hline Tian & 2013 & China & Asian & os & Taqman assay & 133 & 133 & 41 & 62 & 30 & 144 & 122 & 62 & 53 & 18 & 177 & 89 & 0.23 & 9 \\
\hline Gao & 2013 & China & Asian & CRC & PCR-RFLP & 347 & 488 & 175 & 144 & 28 & 494 & 200 & 216 & 210 & 62 & 642 & 334 & 0.33 & 7.5 \\
\hline Bensen-1 & 2013 & America & African & $\mathrm{BC}$ & $\begin{array}{l}\text { Genotyping } \\
\text { array }\end{array}$ & 742 & 658 & 362 & 317 & 63 & 1041 & 443 & 343 & 257 & 58 & 943 & 373 & 0.32 & 8 \\
\hline Bensen-2 & 2013 & America & Caucasian & $\mathrm{BC}$ & $\begin{array}{l}\text { Genotyping } \\
\text { array }\end{array}$ & 1203 & 1088 & 496 & 563 & 144 & 1555 & 851 & 430 & 503 & 155 & 1363 & 813 & 0.69 & 8 \\
\hline Yin & 2013 & China & Asian & $\mathrm{ESCC}$ & PCR-LDR & 629 & 686 & 277 & 278 & 45 & 832 & 368 & 310 & 290 & 73 & 910 & 436 & 0.68 & 9.5 \\
\hline Son & 2013 & Korea & Asian & $\mathrm{HCC}$ & PCR-RFLP & 157 & 201 & 69 & 75 & 13 & 213 & 101 & 110 & 74 & 17 & 294 & 108 & 0.37 & 7 \\
\hline $\mathrm{Xu}$ & 2011 & China & Asian & $\mathrm{HCC}$ & PCR-RFLP & 502 & 549 & 204 & 236 & 62 & 644 & 360 & 266 & 229 & 54 & 761 & 337 & 0.65 & 10 \\
\hline Krzysztof & 2011 & Poland & Caucasian & LL & PCR-RFLP & 195 & 200 & 79 & 88 & 28 & 246 & 144 & 98 & 83 & 19 & 279 & 121 & 0.81 & 7 \\
\hline
\end{tabular}

NPC nasopharyngeal carcinoma, PC prostate cancer, HCC hepatocellular carcinoma, OS osteosarcoma, CRC colorectal cancer, BC breast cancer, ESCC esophageal squamous cell cancer, LL lymphocytic leukemia, RCC renal cell cancer, CC cervical cancer, GC gastric cancer, PTC papillary thyroid carcinoma,

PCR-RFLP polymerase chain reaction-restriction fragment length polymorphism, PCR-LDR polymerase chain reaction-ligation detection reaction, MALDI-TOF MS matrix-assisted laser desorption/ionization time-of-flight mass spectrometry.

gastric cancer risk in the comparison model of $\mathrm{C}$ versus $\mathrm{T}$ $\left(\mathrm{P}_{\mathrm{H}}=0.843, \mathrm{OR}=0.758\right.$, and $\left.95 \% \mathrm{CI}=0.643-0.893\right)$, CT versus TT $\left(\mathrm{P}_{\mathrm{H}}=0.381, \mathrm{OR}=0.755\right.$, and $95 \% \mathrm{CI}=0.598$ $0.953), \mathrm{CC}$ versus TT $\left(\mathrm{P}_{\mathrm{H}}=0.400, \mathrm{OR}=0.584\right.$, and $95 \%$ $\mathrm{CI}=0.405-0.842), \mathrm{CC} / \mathrm{CT}$ versus $\mathrm{TT}\left(\mathrm{P}_{\mathrm{H}}=0.664, \mathrm{OR}=\right.$ 0.715 , and $95 \% \mathrm{CI}=0.574-0.892)$, and $\mathrm{CC}$ versus $\mathrm{CT} / \mathrm{TT}$ $\left(\mathrm{P}_{\mathrm{H}}=0.254, \mathrm{OR}=0.667\right.$, and $\left.95 \% \mathrm{CI}=0.471-0.943\right)$. The rs4938723 polymorphism showed also reverse correlation with esophageal squamous cell cancer in the comparison model of CC versus TT $\left(\mathrm{P}_{\mathrm{H}}=0.345, \mathrm{OR}=0.787\right.$, and $95 \%$ $\mathrm{CI}=0.638-0.972)$ and $\mathrm{CC}$ versus $\mathrm{CT} / \mathrm{TT}\left(\mathrm{P}_{\mathrm{H}}=0.164\right.$, $\mathrm{OR}=0.774$, and $95 \% \mathrm{CI}=0.633-0.947)$.

\section{Publication bias and sensitivity analysis}

Begger's funnel plot and Egger's test were employed to evaluate the possible publication bias in our study. As shown in Table 2 and Figure 3, no evidence of publication bias was detected in all comparisons. Sensitivity analysis was performed to examine the influence of the individual data set to the pooled ORs. As shown in Figure 4, the pooled ORs and 95\% CIs were not significantly altered when any part of the study was individually omitted. These data indicate that the results of our meta-analysis are reliable.

\section{Cumulative meta-analysis}

According to the chronological order of the cumulative analysis, OR point estimates and confidence intervals were stable and exhibited a good change of trend, as shown in Figure 5.

\section{DISCUSSION}

The miR-34 family is largely considered a tumor suppressor miRNA [34, 35]. miR-34b/c is located on chromosome 11q23, and has tissue-specific functions and different expression patterns in various cancers [36]. The miR-34b/c gene rs4938723 polymorphism has been investigated because of its potential association with the increased risk for cancer development [13-15, 17]; 
however, the results remain inconclusive. This updated meta-analysis was performed to obtain conclusive results about the association of rs4938723 polymorphism and cancer risk. A total of 10,812 cancer cases and 11,719 healthy controls were retrieved for the analysis. An increased risk for cancer was observed for the rs4938723 polymorphism under overdominant (CT vs. CC/TT) model. A stratified analysis showed that this association was observed in people with hepatocellular carcinoma, colorectal cancer, gastric cancer, and esophageal squamous cell cancer. Our results indicate that the rs4938723 polymorphism is a risk factor for cancer.

Several meta-analyses investigated the association between $\mathrm{miR}-34 \mathrm{~b} / \mathrm{c}$ gene rs4938723 polymorphism and cancer risk $[11,12,37]$. In the study conducted by Qiu et al., the meta-analysis included 11 studies, and indicated that allele $\mathrm{C}$ and genotype $\mathrm{CT}$ might be risk factors for hepatocellular cancer, and protective factors for colorectal cancer [37]. The meta-analysis conducted by Li et al. included 13 studies, and indicated that the rs4938723

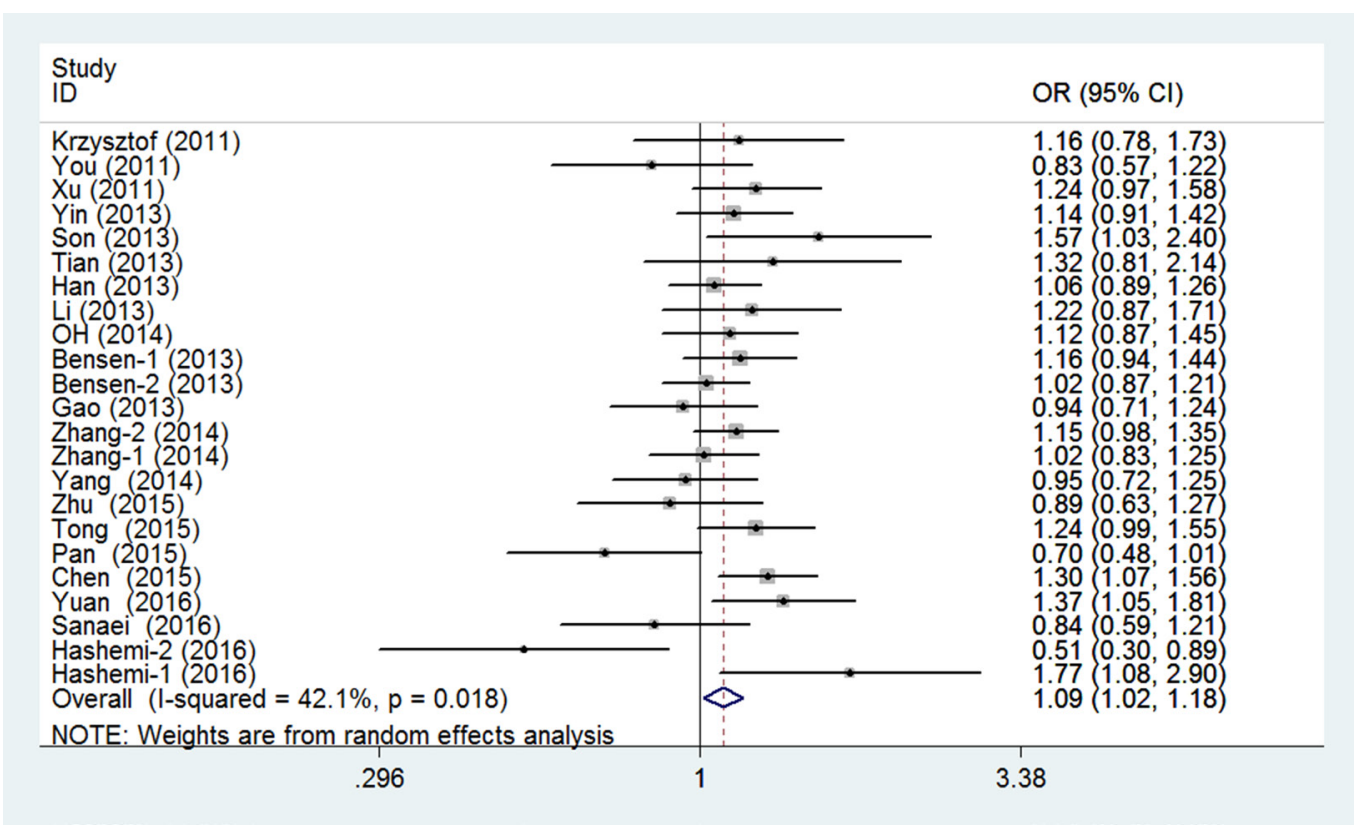

Figure 2: Forest plots of the association between miR-34b/c gene rs4938723 and cancer susceptibility (overdominant model).

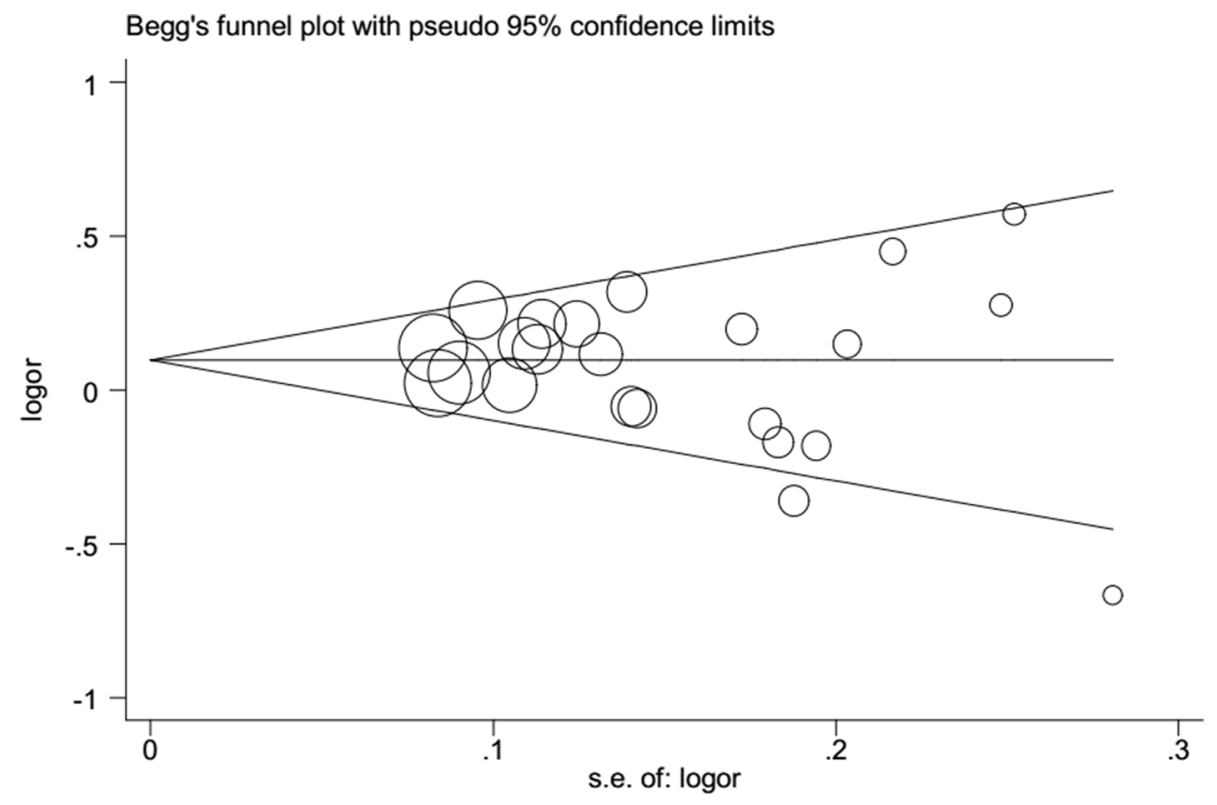

Figure 3: Publication bias tested by Begg's funnel plot in general population. Models represented in overdominant model. 
Table 2: ORs and 95\% CI for cancer risk and pri-miR-34b/c polymorphism (rs4938723 $\mathrm{T}>\mathrm{C}$ ) under different genetic models

\begin{tabular}{|c|c|c|c|c|c|c|c|c|c|}
\hline \multirow{2}{*}{ Comparison } & \multirow{2}{*}{ Subgroup } & \multirow{2}{*}{$N$} & \multicolumn{2}{|c|}{ Heterogeneity test } & \multirow{2}{*}{$\begin{array}{c}Z \text { test } \\
P_{Z}\end{array}$} & \multicolumn{2}{|c|}{ Publication bias } & \multicolumn{2}{|c|}{ OR and $95 \% \mathrm{CI}$} \\
\hline & & & $\mathbf{P}_{\mathrm{H}}$ & $I^{2}(\%)$ & & $P_{B}$ & $P_{E}$ & Fixed model & Random model \\
\hline \multirow[t]{9}{*}{ C vs. T } & Overall & 23 & 0 & 75.7 & 0.356 & 0.492 & 0.677 & $1.031(0.991-1.072)$ & $1.041(0.956-1.134)$ \\
\hline & Asian & 20 & 0 & 77.2 & 0.470 & & & $1.037(0.993-1.084)$ & $1.037(0.940-1.143)$ \\
\hline & Caucasian & 2 & 0.018 & 82.1 & 0.668 & & & $0.969(0.867-1.084)$ & $1.086(0.746-1.580)$ \\
\hline & LL & 3 & 0.002 & 83.9 & 0.571 & & & $0.929(0.808-1.068)$ & $0.886(0.582-1.349)$ \\
\hline & ESCC & 4 & 0.898 & 0 & 0.225 & & & $0.947(0.867-1.034)$ & $0.947(0.867-1.034)$ \\
\hline & $\mathrm{HCC}$ & 3 & 0.113 & 54.2 & 0.036 & & & $1.114(1.007-1.233)$ & $1.151(0.974-1.360)$ \\
\hline & $\mathrm{CRC}$ & 2 & 0.154 & 50.9 & 0.058 & & & $0.870(0.754-1.005)$ & $0.867(0.706-1.066)$ \\
\hline & $\mathrm{BC}$ & 3 & 0.304 & 16.1 & 0.556 & & & $0.973(0.888-1.066)$ & $0.978(0.881-1.085)$ \\
\hline & GC & 2 & 0.843 & 0 & 0.001 & & & $0.758(0.643-0.893)$ & $0.758(0.643-0.893)$ \\
\hline \multirow[t]{9}{*}{ CT vs. TT } & Overall & 23 & 0 & 60.6 & 0.061 & 0.833 & 0.825 & $1.099(1.040-1.162)$ & $1.094(0.996-1.203)$ \\
\hline & Asian & 20 & 0 & 64.1 & 0.118 & & & $1.107(1.041-1.177)$ & $1.091(0.978-1.217)$ \\
\hline & Caucasian & 2 & 0.192 & 41.2 & 0.853 & & & $1.015(0.863-1.195)$ & $1.061(0.809-1.392)$ \\
\hline & LL & 3 & 0.011 & 77.9 & 0.788 & & & $1.047(0.865-1.267)$ & $0.936(0.578-1.515)$ \\
\hline & ESCC & 4 & 0.599 & 0 & 0.552 & & & $1.038(0.919-1.172)$ & $1.038(0.919-1.172)$ \\
\hline & $\mathrm{HCC}$ & 3 & 0.121 & 52.6 & 0.016 & & & $1.191(1.033-1.373)$ & $1.250(0.993-1.573)$ \\
\hline & $\mathrm{CRC}$ & 2 & 0.222 & 32.9 & 0.741 & & & $0.967(0.795-1.177)$ & $0.964(0.758-1.226)$ \\
\hline & $\mathrm{BC}$ & 3 & 0.289 & 19.5 & 0.760 & & & $1.020(0.897-1.161)$ & $1.020(0.878-1.185)$ \\
\hline & $\mathrm{GC}$ & 2 & 0.381 & 0 & 0.018 & & & $0.755(0.598-0.953)$ & $0.755(0.598-0.953)$ \\
\hline \multirow[t]{9}{*}{ CC vs. TT } & Overall & 23 & 0 & 72.1 & 0.794 & 0.460 & 0.622 & $0.994(0.908-1.088)$ & $1.025(0.851-1.234)$ \\
\hline & Asian & 20 & 0 & 73.9 & 0.872 & & & $1.008(0.911-1.115)$ & $1.018(0.822-1.261)$ \\
\hline & Caucasian & 2 & 0.022 & 80.8 & 0.737 & & & $0.904(0.710-1.151)$ & $1.146(0.517-2.539)$ \\
\hline & LL & 3 & 0.005 & 81.3 & 0.568 & & & $0.745(0.529-1.048)$ & $0.744(0.270-2.051)$ \\
\hline & ESCC & 4 & 0.345 & 9.5 & 0.026 & & & $0.787(0.638-0.972)$ & $0.794(0.632-0.998)$ \\
\hline & $\mathrm{HCC}$ & 3 & 0.285 & 20.4 & 0.221 & & & $1.150(0.919-1.439)$ & $1.172(0.895-1.535)$ \\
\hline & $\mathrm{CRC}$ & 2 & 0.342 & 0 & 0.015 & & & $0.658(0.470-0.923)$ & $0.661(0.471-0.928)$ \\
\hline & $\mathrm{BC}$ & 3 & 0.386 & 0 & 0.300 & & & $0.897(0.730-1.102)$ & $0.896(0.729-1.102)$ \\
\hline & $\mathrm{GC}$ & 2 & 0.400 & 0 & 0.004 & & & $0.584(0.405-0.842)$ & $0.584(0.405-0.842)$ \\
\hline \multirow[t]{9}{*}{ CC/CT vs. TT } & Overall & 23 & 0 & 70.9 & 0.145 & 0.792 & 0.890 & $1.078(1.022-1.137)$ & $1.081(0.974-1.199)$ \\
\hline & Asian & 20 & 0 & 73.1 & 0.229 & & & $1.086(1.024-1.152)$ & $1.076(0.955-1.213)$ \\
\hline & Caucasian & 2 & 0.060 & 71.8 & 0.638 & & & $0.992(0.850-1.157)$ & $1.100(0.738-1.640)$ \\
\hline & $\mathrm{LL}$ & 3 & 0.005 & 81.5 & 0.688 & & & $0.986(0.821-1.184)$ & $0.902(0.545-1.493)$ \\
\hline & ESCC & 4 & 0.891 & 0 & 0.881 & & & $0.991(0.882-1.113)$ & $0.991(0.882-1.113)$ \\
\hline & $\mathrm{HCC}$ & 3 & 0.090 & 58.6 & 0.065 & & & $1.184(1.034-1.354)$ & $1.248(0.987-1.577)$ \\
\hline & $\mathrm{CRC}$ & 2 & 0.157 & 50 & 0.288 & & & $0.904(0.750-1.089)$ & $0.899(0.690-1.171)$ \\
\hline & $\mathrm{BC}$ & 3 & 0.287 & 19.9 & 0.958 & & & $0.997(0.882-1.127)$ & $0.999(0.866-1.153)$ \\
\hline & GC & 2 & 0.664 & 0 & 0.003 & & & $0.715(0.574-0.892)$ & $0.715(0.574-0.892)$ \\
\hline \multirow[t]{9}{*}{$\mathrm{CC}$ vs. CT/TT } & Overall & 23 & 0 & 64.0 & 0.704 & 0.561 & 0.557 & $0.946(0.868-1.031)$ & $0.970(0.830-1.134)$ \\
\hline & Asian & 20 & 0 & 66.7 & 0.702 & & & $0.954(0.867-1.050)$ & $0.965(0.806-1.157)$ \\
\hline & Caucasian & 2 & 0.049 & 74.2 & 0.829 & & & $0.897(0.716-1.124)$ & $1.073(0.564-2.043)$ \\
\hline & LL & 3 & 0.008 & 79.2 & 0.521 & & & $0.703(0.507-0.976)$ & $0.739(0.294-1.860)$ \\
\hline & ESCC & 4 & 0.164 & 41.2 & 0.013 & & & $0.774(0.633-0.947)$ & $0.815(0.612-1.086)$ \\
\hline & $\mathrm{HCC}$ & 3 & 0.493 & 0 & 0.579 & & & $1.062(0.859-1.314)$ & $1.062(0.859-1.314)$ \\
\hline & $\mathrm{CRC}$ & 2 & 0.519 & 0 & 0.016 & & & $0.672(0.485-0.930)$ & $0.674(0.486-0.934)$ \\
\hline & $\mathrm{BC}$ & 3 & 0.387 & 0 & 0.241 & & & $0.890(0.733-1.081)$ & $0.889(0.732-1.081)$ \\
\hline & GC & 2 & 0.254 & 23.1 & 0.022 & & & $0.667(0.471-0.943)$ & $0.678(0.452-1.017)$ \\
\hline \multirow[t]{9}{*}{$\mathrm{CT}$ vs.CC/TT } & Overall & 23 & 0.018 & 42.1 & 0.018 & 0.428 & 0.423 & $1.101(1.044-1.161)$ & $1.093(1.015-1.177)$ \\
\hline & Asian & 20 & 0.008 & 48.5 & 0.051 & & & $1.105(1.042-1.172)$ & $1.090(1.000-1.189)$ \\
\hline & Caucasian & 2 & 0.57 & 0 & 0.597 & & & $1.042(0.895-1.213)$ & $1.042(0.895-1.213)$ \\
\hline & LL & 3 & 0.014 & 76.5 & 0.849 & & & $1.103(0.919-1.325)$ & $0.957(0.611-1.501)$ \\
\hline & ESCC & 4 & 0.303 & 17.6 & 0.190 & & & $1.081(0.962-1.214)$ & $1.067(0.932-1.222)$ \\
\hline & $\mathrm{HCC}$ & 3 & 0.195 & 38.9 & 0.035 & & & $1.157(1.010-1.324)$ & $1.192(0.986-1.441)$ \\
\hline & $\mathrm{CRC}$ & 2 & 0.357 & 0 & 0.729 & & & $1.034(0.856-1.249)$ & $1.034(0.856-1.249)$ \\
\hline & $\mathrm{BC}$ & 3 & 0.299 & 17.1 & 0.495 & & & $1.044(0.923-1.179)$ & $1.041(0.950-1.197)$ \\
\hline & $\mathrm{GC}$ & 2 & 0.193 & 41.1 & 0.140 & & & $0.847(0.680-1.056)$ & $0.833(0.620-1.119)$ \\
\hline
\end{tabular}

$P_{H}: P$-value of heterogeneity test; $P_{Z}: P$-value of $Z$ test; $P_{B}: P$-value of Begg's test; $P_{E}: P$-value of Egger's test; OR: odds ratio; $95 \%$ CI: $95 \%$ confidence interval; $N$ : number of comparisons. 


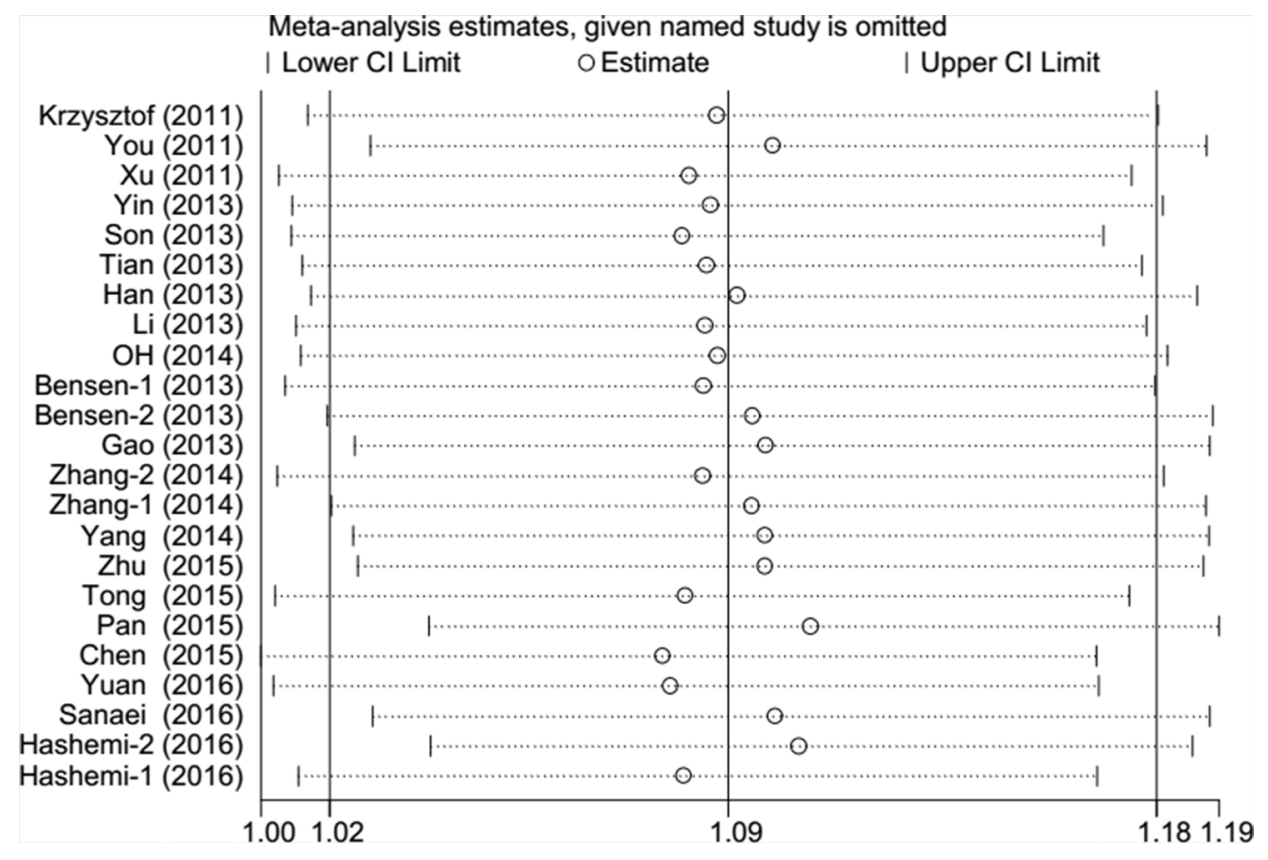

Figure 4: Sensitivity analysis of each study included in this meta-analysis by omitting each data set in the metaanalysis (overdominant model).

Study
ID

Figure 5: Cumulative analysis according to the chronological order (overdominant model). 
polymorphism was associated with an increased cancer susceptibility of the Asian population. However, the polymorphism reduced susceptibility to colorectal cancer and esophageal squamous cell cancer in Asians [11, 12].

Nine studies have been conducted from 2014 to 2016 [13-9, 32, 33]. These studies comprised 3,059 cases and 3,705 controls and were included in our current metaanalysis. Thus, our meta-analysis increased the number of relevant studies compared to previous meta-analyses. Our study had relatively large study number, thus we could conduct more subgroup analyses based on different ethnicities and types of cancer. The statistical power of our meta-analysis was significantly increased. Consistent with the previous meta-analyses, we observed an increased risk for cancer that was associated with the miR-34b/c gene rs4938723 polymorphism using the overdominant model.

Different cancer types might contribute differently to the overall result of our meta-analysis. In our analysis, 12 types of cancers were included. In the stratified analysis, the rs4938723 polymorphisms were associated with an increased risk of hepatocellular carcinoma, but with a decreased risk for colorectal, gastric, and esophageal squamous cell cancer.

Some limitations in this study should be mentioned: First, only studies in English and Chinese were included. Second, the number of included studies in some cancer types, such as gastric cancer, was relatively small. Nasopharyngeal carcinoma, osteosarcoma, renal cell cancer, cervical cancer, prostate cancer, and papillary thyroid carcinoma were each included only once, making stratification impossible. Therefore, the statistical power might be insufficient to assess the relationship in these cancers. Third, the studies included were mostly performed in the Asian population; two studies were in the Caucasian population, and one study was performed in the African population. Thus, large-scale studies including different cancer types and populations should be conducted in the future. Finally, some important confounding factors that contribute to cancer susceptibility, such as age, gender, and smoking, were not included in the stratified analysis and should be analyzed in future.

\section{MATERIALS AND METHODS}

\section{Searching and screening eligible studies}

In the present study, we conducted a comprehensive search of the PubMed, Embase, Web of Science, Wanfang, and CNKI databases to identify all potentially eligible studies on rs4938723 polymorphism and cancer risk. The last search was updated on December 22, 2016, by using the following search terms: (pre-mir-34b/c OR pri-miR34b/c OR mir-34b/c OR microRNA-34b/c OR rs4938723), (gene OR polymorphism OR allele OR variation), and (cancer OR carcinoma OR tumor). We also manually searched the references of previous meta-analyses and reviews to identify other studies. All of the selected studies in our meta-analysis conformed to all of the following criteria: (1) case-control studies; (2) evaluation of rs4938723 polymorphism and cancer risk; (3) sufficient genotype frequency data for calculating the OR and 95\% CI; and (4) genotype distribution of the control group that was consistent with the HWE. The major exclusion criteria were as follows: (1) duplicates of previous publications; (2) studies irrelevant to cancer or miRNA-SNPs; and (3) no available data used for the SNPs.

\section{Data extraction and quality assessment}

Two authors (HL and BXM) independently reviewed and determined whether an individual study was eligible for inclusion. A third reviewer would participate if any discrepancy was encountered, and a final decision was made by the majority of the votes. The following data were extracted from each eligible study: (1) the surname of the first author, (2) year of publication, (3) country, (4) ethnicity, (5) cancer type, (6) number of controls and cases, (7) allele or genotype frequencies of cases and controls, and (8) HWE of the control subjects. The quality assessment for each eligible study was assessed according to a methodological quality assessment scale that was extracted and modified from previous studies [38]. Six items were assessed. The quality scores ranged from 0 to 10 .

\section{Statistics}

The strength of the association between rs4938723 polymorphism and cancer risk was assessed by ORs and corresponding 95\% CIs under five different genetic models. The models were as follows: allele model (C vs. $\mathrm{T}$ ), genotype model (CT vs. TT and CC vs. TT), dominant model (CC/CT vs. TT), recessive model (CC vs. CT/ TT), and over-dominant model (CT vs. CC/TT). $p<0.05$ was considered statistically significant. We conducted subgroup analysis according to ethnicity and cancer type. Heterogeneity among studies was examined with Cochran's $Q$ test and the $I^{2}$ statistic [39]. A random-effect model was used if the $p$ value of the heterogeneity tests was no more than 0.1 ( $p \leq 0.1)$; otherwise, the fixed-effect model was used. Analysis was performed by using the STATA 11.0 (Stata Corporation, College Station, TX, USA).

\section{CONCLUSIONS}

In summary, our study shows that the miR$34 \mathrm{~b} / \mathrm{c}$ gene rs4938723 is a susceptible locus for cancer. The rs4938723 polymorphisms are associated with an increased risk for hepatocellular carcinoma, but decreased risk for colorectal, gastric, and esophageal squamous cell cancer. 


\section{Abbreviations}

miRNAs, microRNAs; SNPs, single nucleotide polymorphisms; HWE, Hardy-Weinberg equilibrium; NPC, nasopharyngeal carcinoma; HCC, hepatocellular carcinoma; OS, osteosarcoma; CRC, colorectal cancer; $\mathrm{BC}$, breast cancer; ESCC, esophageal squamous cell cancer; LL, lymphocytic leukemia; RCC, renal cell cancer; $\mathrm{CC}$, cervical cancer; GC, gastric cancer; PTC, papillary thyroid carcinoma

\section{Authors' contributions}

$\mathrm{Li} \mathrm{H}$ and Ma BX were involved in the conception and design of the study. Li H and Diao SL performed the literature searches, data extraction, and analyses. Li H, Diao SL and Yuan SH assessed the data quality. Li H, Diao SL, Li JS and Ma BX contributed to data analysis and interpretation of the results. All authors reviewed and approved the final manuscript.

\section{CONFLICTS OF INTEREST}

The authors declare that there are no conflicts of interest in this work.

\section{FUNDING}

This research received no specific grant from any funding agency in the public, commercial, or not for-profit sectors.

\section{REFERENCES}

1. Chandra V, Lee YM, Gupta U, Mittal B, Kim JJ, Rai R. Quantitative assessment of CD44 genetic variants and cancer susceptibility in Asians: a meta-analysis. Oncotarget. 2016; 7:74286-74302. doi: 10.18632/oncotarget.10951.

2. Wang Y, Han Y, Weng Q, Yuan Z. Predictive value of XPG rs2296147T $>$ C polymorphism on clinical outcomes of cancer patients. Oncotarget. 2016; 7:65770-65781. doi: 10.18632/oncotarget.11664.

3. Yuan Z, Li J, Hu R, Jiao Y, Han Y, Weng Q. Predictive assessment in pharmacogenetics of XRCC1 gene on clinical outcomes of advanced lung cancer patients treated with platinum-based chemotherapy. Sci Rep. 2015; 5:16482.

4. Bartel DP. MicroRNAs: target recognition and regulatory functions. Cell. 2009; 136:215-233.

5. Wang LQ, Kwong YL, Wong KF, Kho CS, Jin DY, Tse E, Rosen A, Chim CS. Epigenetic inactivation of mir-34b/c in addition to mir-34a and DAPK1 in chronic lymphocytic leukemia. J Transl Med. 2014; 12:52.

6. Nadal E, Chen G, Gallegos M, Lin L, Ferrer-Torres D, Truini A, Wang Z, Lin J, Reddy RM, Llatjos R, Escobar I,
Moya J, Chang AC, et al. Epigenetic inactivation of microRNA-34b/c predicts poor disease-free survival in early-stage lung adenocarcinoma. Clin Cancer Res. 2013;19:6842-6852.

7. Yin J, Wang X, Zheng L, Shi Y, Wang L, Shao A, Tang W, Ding G, Liu C, Liu R, Chen S, Gu H. Hsa-miR-34b/c rs4938723 $\mathrm{T}>\mathrm{C}$ and hsa-miR-423 rs6505162 $\mathrm{C}>\mathrm{A}$ polymorphisms are associated with the risk of esophageal cancer in a Chinese population. PLoS One. 2013;8:e80570.

8. Nicoloso MS, Sun H, Spizzo R, Kim H, Wickramasinghe P, Shimizu M, Wojcik SE, Ferdin J, Kunej T, Xiao L, Manoukian S, Secreto G, Ravagnani F, et al. Single-nucleotide polymorphisms inside microRNA target sites influence tumor susceptibility. Cancer Res. 2010; 70:2789-2798.

9. Hiyoshi Y, Schetter AJ, Okayama H, Inamura K, Anami K, Nguyen GH, Horikawa I, Hawkes JE, Bowman ED, Leung SY, Harris CC. Increased microRNA-34b and -34c predominantly expressed in stromal tissues is associated with poor prognosis in human colon cancer. PLoS One. 2015; 10:e0124899.

10. Ji TX, Zhi C, Guo XG, Zhou Q, Wang GQ, Chen B, Ma FF. MiR-34b/c rs4938723 Polymorphism Significantly Decreases the Risk of Digestive Tract Cancer: Metaanalysis. Asian Pac J Cancer Prev. 2015; 16:6099-6104.

11. Lin Z, Chen L, Song M, Shi KQ, Tang KF. Association between a polymorphism in miR-34b/c and susceptibility to cancer--a meta-analysis. Asian Pac J Cancer Prev. 2014; 15:7251-7255.

12. Li X, Wang L, Yu J, Xu J, Du J. The genetic association between pri-miR-34b/c polymorphism (rs4938723 $\mathrm{T}>$ C) and susceptibility to cancers: evidence from published studies. Tumour Biol. 2014; 35:12525-12534.

13. Yuan F, Sun R, Chen P, Liang Y, Ni S, Quan Y, Huang J, Zhang L, Gao L. Combined analysis of pri-miR-34b/c rs4938723 and TP53 Arg72Pro with cervical cancer risk. Tumour Biol. 2016; 37:6267-6273.

14. Tong N, Chu H, Wang M, Xue Y, Du M, Lu L, Zhang H, Wang F, Fang Y, Li J, Wu D, Zhang Z, Sheng X. PrimiR-34b/c rs4938723 polymorphism contributes to acute lymphoblastic leukemia susceptibility in Chinese children. Leuk Lymphoma. 2016; 57:1436-1441.

15. Sanaei S, Hashemi M, Rezaei M, Hashemi SM, Bahari G, Ghavami S. Evaluation of the pri-miR-34b/c rs4938723 polymorphism and its association with breast cancer risk. Biomed Rep. 2016; 5:125-129.

16. Zhu JB, Yang L, You WY, Cui XB, Chen YZ, Hu JM, Liu W, Li SG, Song XY, Wei YT, Zhang WJ, Li F. Genetic variation in miR-100 rs1834306 is associated with decreased risk for esophageal squamous cell carcinoma in Kazakh patients in northwest China. Int J Clin Exp Pathol. 2015; 8:7332-7340.

17. Pan XM, Sun RF, Li ZH, Guo XM, Qin HJ, Gao LB. Pri-miR-34b/c rs4938723 polymorphism is associated with a decreased risk of gastric cancer. Genet Test Mol Biomarkers. 2015; 19:198-202. 
18. Chen P, Sun RF, Pu Y, Bai P, Yuan F, Liang YD, Zhou B, Wang YY, Sun YH, Zhu JQ, Zhang L, Gao LB. Pri-Mir34b/C and Tp-53 Polymorphisms are Associated With The Susceptibility of Papillary Thyroid Carcinoma A CaseControl Study. Medicine (Baltimore). 2015; 94,e1536.

19. Yang C, Ma X, Liu D, Wang Y, Tang R, Zhu Y, Xu Z, Yang L. Promoter polymorphisms of $\mathrm{miR}-34 \mathrm{~b} / \mathrm{c}$ are associated with risk of gastric cancer in a Chinese population. Tumour Biol. 2014; 35:12545-12554.

20. Zhang S, Qian J, Cao Q, Li P, Wang M, Wang J, Ju X, Meng X, Lu Q, Shao P, Zhang Z, Qin C, Yin C. A potentially functional polymorphism in the promoter region of $\mathrm{miR}-34 \mathrm{~b} / \mathrm{c}$ is associated with renal cell cancer risk in a Chinese population. Mutagenesis. 2014; 29:149-154.

21. Zhang J, Huang X, Xiao J, Yang Y, Zhou Y, Wang X, Liu Q, Yang J, Wang M, Qiu L, Zheng Y, Zhang P, Li J, et al. Pri-miR-124 rs531564 and pri-miR-34b/c rs4938723 polymorphisms are associated with decreased risk of esophageal squamous cell carcinoma in Chinese populations. PLoS One. 2014; 9:e100055.

22. Oh J, Kim JW, Lee BE, Jang MJ, Chong SY, Park PW, Hwang SG, Oh D, Kim NK. Polymorphisms of the pri-miR$34 \mathrm{~b} / \mathrm{c}$ promoter and TP53 codon 72 are associated with risk of colorectal cancer. Oncol Rep. 2014; 31:995-1002.

23. Son MS, Jang MJ, Jeon YJ, Kim WH, Kwon CI, Ko KH, Park PW, Hong SP, Rim KS, Kwon SW, Hwang SG, Kim NK. Promoter polymorphisms of pri-miR-34b/c are associated with hepatocellular carcinoma. Gene. 2013; 524:156-160.

24. Li L, Wu J, Sima X, Bai P, Deng W, Deng X, Zhang L, Gao L. Interactions of miR-34b/c and TP-53 polymorphisms on the risk of nasopharyngeal carcinoma. Tumour Biol. 2013; 34:1919-1923.

25. Han Y, Pu R, Han X, Zhao J, Zhang Y, Zhang Q, Yin J, Xie J, Shen Q, Deng Y, Ding Y, Li W, Li J, et al. Associations of pri-miR-34b/c and pre-miR-196a2 polymorphisms and their multiplicative interactions with hepatitis $\mathrm{B}$ virus mutations with hepatocellular carcinoma risk. PLoS One. 2013; 8:e58564.

26. Gao LB, Li LJ, Pan XM, Li ZH, Liang WB, Bai P, Zhu YH, Zhang L. A genetic variant in the promoter region of miR$34 \mathrm{~b} / \mathrm{c}$ is associated with a reduced risk of colorectal cancer. Biol Chem. 2013; 394:415-420.

27. Bensen JT, Tse CK, Nyante SJ, Barnholtz-Sloan JS, Cole SR, Millikan RC. Association of germline microRNA SNPs in pre-miRNA flanking region and breast cancer risk and survival: the Carolina Breast Cancer Study. Cancer Causes \& Control. 2013; 24:1099-1109.

28. Xu Y, Liu L, Liu J, Zhang Y, Zhu J, Chen J, Liu S, Liu Z, Shi H, Shen H, Hu Z. A potentially functional polymorphism in the promoter region of $\mathrm{miR}-34 \mathrm{~b} / \mathrm{c}$ is associated with an increased risk for primary hepatocellular carcinoma. Int J Cancer. 2011; 128:412-417.

29. Tian Q, Jia J, Ling S, Liu Y, Yang S, Shao Z. A causal role for circulating miR-34b in osteosarcoma. Eur J Surg Oncol. 2014; 40:67-72.

30. Jamroziak K SJ, Rawstron A, Szemraj-Rogucka Z, Grzybowska-Izydorczyk O, Giannopoulos K. Polymorphisms of mir-34b/c, mir-146a and mir-196a-2 and predisposition to chronic lymphocytic leukemia and monoclonal b-cell lymphocytosis. Blood. 2011; 118:4585.

31. You WY[Master's thesis]. A case-control study on the association between polymorphisms of microRNA genes and susceptibility for Kazakh's esophageal cancer. Shihezi University. 2011.

32. Hashemi M BG, Naderi M, Sadeghi-Bojd S, Taheri M. Pri$\mathrm{miR}-34 \mathrm{~b} / \mathrm{c} \mathrm{rs} 4938723$ polymorphism is associated with the risk of childhood acute lymphoblastic leukemia. Cancer Genet. 2016; 209:493-496.

33. Hashemi M, Danesh H, Bizhani F, Narouie B, Sotoudeh M, Nouralizadeh A, Sharifiaghdas F, Bahari G, Taheri M. PrimiR-34b/c rs4938723 polymorphism increased the risk of prostate cancer. Cancer Biomark. 2017; 18:155-159.

34. Hermeking $\mathrm{H}$. The miR-34 family in cancer and apoptosis. Cell Death Differ. 2010; 17:193-199.

35. Vogt M, Munding J, Gruner M, Liffers ST, Verdoodt B, Hauk J, Steinstraesser L, Tannapfel A, Hermeking H. Frequent concomitant inactivation of miR-34a and miR$34 \mathrm{~b} / \mathrm{c}$ by $\mathrm{CpG}$ methylation in colorectal, pancreatic, mammary, ovarian, urothelial, and renal cell carcinomas and soft tissue sarcomas. Virchows Arch. 2011;458: 313-322.

36. Li H, Li X, Ge X, Jia L, Zhang Z, Fang R, Yang J, Liu J, Peng S, Zhou M, Xiang J, Zeng Z, Zhou W, et al. MiR34b-3 and miR-449a inhibit malignant progression of nasopharyngeal carcinoma by targeting lactate dehydrogenase A. Oncotarget. 2016; 7:54838-54851. doi: 10.18632/oncotarget.10761.

37. Liu Q, Yang G, Song XL, Wang Z, Shi G. Association between rs4938723 functional polymorphism in the promoter region of $\mathrm{miR}-34 \mathrm{~b} / \mathrm{c}$ gene and cancer risk. Clin Res Hepatol Gastroenterol. 2015; 39:526-533.

38. Guo J, Jin M, Zhang M, Chen K. A genetic variant in miR-196a2 increased digestive system cancer risks: a meta-analysis of 15 case-control studies. PLoS One. 2012; 7:e30585.

39. Higgins JP, Thompson SG. Quantifying heterogeneity in a meta-analysis. Stat Med. 2002; 21:1539-1558. 